được cầm máu bằng dao điện trước khi cắt, vì vậy giảm tối đa lượng máu mất trong phẫu thuật.

\section{KẾT LUÂ̂N}

Điều trị UXTC bằng phẫu thuật nội soi cắt tử cung hoàn toàn mang đến nhiều ưu điểm như thời gian phẫu thuật ngắn, diện cắt nhỏ giảm tối đa lượng máu mất trong mổ, có thể thực hiện với những u lớn $>50 \mathrm{~mm}$.

\section{TÀI LIÊU THAM KHẢO}

1. Dướng Thị Cương, Nguyễn Đức Hinh (1999). "U xơ tử cung". Phụ khoa dành cho thầy thuốc thực hành. Nhà xuất bản y hoc, trang 58 - 67.

2. Nguyễn Đức Tú (2019), "Điều trị u xơ tử cung bằng phẫu thuật nội soi cắt tử cung hoàn toàn tại bệnh viện Phụ sản Trung Ương". Luận văn chuyên khoa 2019, Đại học Y Hà Nội.

3. Nguyễn Văn Giáp, (2006). Nghiên cứu ứng dung kỹ thuât cắt tứ cung hoàn toàn qua nôi soi tại Bệnh viện Phụ sản Trung ương, Luận văn tốt nghiệp Bác sĩ chuyên khoa cấp II, Trường Đại học y Hà Nội.

4. Nguyển Văn Lựu (2014), " Nghiên cứu kết qựa cắt tứ cung qua nội soi do u xơ tư cung bằng phẩu thuật nội soi tại Bệnh viện 198-Bộ công an". Luận văn tốt nghiệp.

5. Trương Việ̂t Bắc (2020), "Nhân xét kết quả nọi soi cắt tử cung hoàn toàn điều tri u xơ tử cung tai bệnh viện Phụ sản Hà Nội". Luận văn thạc sĩ 2020, Đai hoc Y Hà Nôi.

6. Trân Thanh Hương (2012), "Nghiên cứu kết quả cắt tử cung hoàn toàn do $u$ xơ tử cung bằng phẫu thuật nội soi tại bệnh viện trung ương quân đội 108". Luận văn tốt nghiệp bác sỹ chuyên khoa cấp II.

7. Parazzini, Tozzi, Biancho (2016). "Pregnancy outcome and uterine fibroids". Best Pract Res Clin Obstet Gynaecol.

8. Wang $X$, Lv L, Cheng Z, Zhou $X$. Curative effect of laparoscopic hysterectomy for uterine fibroids and its impact on ovarian blood supply. Exp Ther Med.

doi:10.3892/etm.2017.4944

\title{
GIÁ TRI CHẨN ĐOÁN CỦA DẤU HIỆU CHAPMAN TRONG CHẨN ĐOÁN NHỒI MÁU Cơ TIM CẤP Ở BỆNH NHÂN CÓ BLOCK NHÁNH TRÁI HOÀN TOÀN
}

\section{TÓM TẮT}

Mục tiêu:Tìm hiểu giá trị chẩn đoán của dấu hiệu Chapman trong chẩn đoán nhồi máu cơ tim cấp ở bệnh nhân có block nhánh trái hoàn toàn. Phương pháp nghiên cứu: Nghiên cứu tiến hành trên 150 bệnh nhân có điện tâm đồ BNT thỏa mãn các tiêu chuẩn chọn bênh tai Viên Tim Mach, bênh viện Bach Mai trong đó 79 bệnh nhân được chẩn đoán NMCT và 71 bênh nhân không được chẩn đoán NMCT. Sau khi tìm hiểu sự hiện diện của các dấu hiện điện tâm đồ trong chẩn đoán NMCT kèm BNT, nghiên cứu sẽ đánh giá khả năng chẩn đoán của dấu Chapman so sánh với các tiêu chuẩn khác trong chẩn đoán NMCT kèm BNT. Kết quả nghiên cứu: Dấu hiệu Chapman là dấu hiệu thường gặp trên điện tâm đồ ở bệnh nhân có BNT(42\%). Dấu hiệu này có độ nhạy $39,2 \%$, độ đặc hiệu $54,9 \%$, giá trị tiên đoán dương $49,2 \%$ và giá trị tiên đoán âm $44.8 \%$ trong chẩn đoán NMCT kèm BNT. Khi kết hợp với men tim giúp cải thiện độ nhạy lên $100 \%$ nhưng làm giảm độ đăc hiêu trong chẩn đoán $(47,9-49,3 \%)$. Khi kết hợp với siêu âm tim giúp cải thiên đô nhay $(67,1-74,7 \%)$ và độ đăc hiêu tốt (97,2\%). Kết luận: Dấu hiệu Chapman là dấu hiệu

\section{${ }^{1}$ Trường đại học Y Hà Nội}

${ }^{2}$ Bênh viên Bach Mai

Chịu trách nhiệm chính: Hà Thị Huê

Email: hahue992@gmail.com

Ngày nhận bài: 24.8.2021

Ngày phản biên khoa hoc: 25.10.2021

Ngày duyệt bài: 3.11.2021
Hà Thị Huêt, Trần Song Giang ${ }^{2}$

thường thấy hơn các dấu hiệu khác trên ĐTĐ ở bệnh nhân NMCT kèm BNT. Giá trị chẩn đoán của dấu hiệu này không cao. Khi kết hợp các thông tin lâm sàng, men tim, siêu âm tim sẽ cải thiện khả năng chẩn đoán. tâm đồ

Tư khóa: Nhồi máu cơ tim, block nhánh trái, điện

\section{SUMMARY \\ THE VALUE OF CHAPMAN'S SIGN IN THE DIAGNOSIS OF ACUTE MYOCARDIAL INFARCTION IN PATIENTS WITH COMPLETE LEFT BUNDLE BRANCH BLOCK}

Objectives: To study the value of Chapman's sign in the diagnosis of acute myocardial infarction in patients with complete left bundle branch block. Methods: The study was conducted on 150 patients with EKG of LBBB satisfying the selection criteria at the Cardiology Institute, Bach Mai hospital in which 79 patients were diagnosed with MI and 71 patients were not diagnosed. diagnose MI. After finding out the prevalence of electrocardiographic signs in the setting of MI with LBBB, we continue evaluate the diagnostic value of Chapman's sign compared with other criteria. Results: Chapman's sign is a common ECG sign in patients with LBBB $(42 \%)$. This sign has a sensitivity of $39.2 \%$, a specificity of $54.9 \%$, a positive predictive value of $49.2 \%$ and a negative predictive value of $44.8 \%$ in the diagnosis of MI with LBBB. When combined with cardiac enzymes, it improves the sensitivity by $100 \%$ but reduces the specificity in diagnosis (47.9 - 49.3\%). 
When combined with echocardiography, it improves sensitivity (67.1 - 74.7\%) and good specificity $(97.2 \%)$. Conclusion: Chapman's sign is more common than other signs on ECG in patients with MI with LBBB. The diagnostic value of this sign is not high. Should combine with clinical information, cardiac enzymes, echocardiography will improve diagnostic ability.

Key words; Chapman's sign; myocardial infarction; branch block

\section{I. ĐĂT VẤN ĐỀ}

Nhồi máu cơ tim cấp là một trong những nguyên nhân hàng đầu gây tử vong ở Hoa Kì và các nước châu Âu. ở Việt Nam số bệnh nhân NMCT cấp ngày càng có xu hướng gia tăng nhanh chóng. Theo một nghiên cứu của Phạm Việt Tuân (2008), trong vòng 5 năm (2003-2007) nhóm bênh nhân bênh tim thiếu máu cuc bô có xuhướng tăng lên từ $11,2 \%$ (năm 2003) lên 24\% (năm 2007). Trong đó, sốbệnh nhân NMCT cấp là 3.662 người, chiếm tî lệ $37,9 \%$, cao nhất trong nhómbệnh tim thiếu máu cục bộ ${ }^{1}$.

Chẩn đoán NMCT cấp thường dựa vào khai thác lâm sàng, làm điện tâm đồ, men tim, và các phương pháp chẩn đoánhình ảnh. Trong đó, điện tâm đồvẫn là một phương pháp giá trị, hết sức đơn giản và tiện lợi để đánh giá những bênh nhân có triệu chứng gợiý NMCT cấp.Tuy nhiên, một số trường hợp sự thay đổi trên điện tâm đồ không rõ ràng hoặc có rối loạn dẫn truyền trong thất như BNT sẽ làm cho việ̣c chẩn đoán NMCT cấp trở nên khó khăn hơn cũ̃ng như bỏ sót, làm chậm trễ quá trình cấp cứu cho bệnh nhân dẫn tới điều trị không phù hợp.

Trên những bệnh nhân điện tâm đồ có BNT hoàn toàn, những rối loạn tái cực thất sẽ làm biến đổi ST-T, từ đó những tiểu chuẩn chẩn đoán NMCT cấp dựa trên biến đổi ST-T không áp dụng được ${ }^{2}$. Do đó, vấn đề đặt ra là liệu điện tâm đồ có còn giá trị để chẩn đoán NMCT cấp không? Những tiêu chuẩn gì có thể giúp chẩn đoán NMCT cấp khi có block nhánh?

Tiêu chuẩn Chapman được mô tả lần đầu tiên vào năm 1957 do Myron G. Chapman. Nghiên cứu đầu tiên cho thấy tiêu chuẩn này độ nhạy thấp (khoảng 3\%), nhưng độ đặc hiệu cao, có thể lên tới $92 \%{ }^{3}$. Các nghiên cứu cho thây tiêu chuẩn Chapman có thể giúp chẩn đoánNMCT cấp ở những bệnh nhân cóBNT và không đáp ứng các tiêu chuẩn Sgarbossa cải tiến. Tuy vậy, tại Việt Nam còn rất ít nghiên cứu về vấn đề này, do vậy chúng tôi tiến hành nghiên cứu nhằm tìm hiểu giá trị của dấu hiệu Chapman trong chẩn đoán NMCT cấp kèm BNT trong thực hành lâm sàng.

\section{II. ĐỐI TƯỢNG VÀ PHƯƠNG PHÁP NGHIÊN CỨU}

Đối tượng nghiên cứu. Nghiên cứu tiến hành theo phương pháp mô tả cắt ngang từ tháng 7/2020 đến tháng 7/2021 trên79 bệnh nhân NMCT cấp, kèm BNT có so sánh với nhóm chứng là 71 bệnh nhân không có bệnh mạch vành nhưng ĐTÐ có hình ảnh BNT hoàn toàn. Chúng tôi không đưa vào nghiên cứu những bệnh nhân có điện tâm đồ lưu trữ bị hỏng không đọc được, điện tầm đồ có rối loạn nhịp thất, hội chứng tiền kích thích.

Các bước tiến hành nghiên cứu. Những bệnh nhân thỏa mãn tiêu chuẩn chọn lựa và không có các tiêu chuẩn loại trừ sẽ được thăm khám lâm sàng và chỉ định các xét nghiệm cân lâm sàng một cách có hệ thống hoặc ghi nhận thông tin từ hồ sơ bệnh án với những bệnh nhẩn hồi cứu. Các bênh nhân sẽ được tiến hành điều trị theo phác đồ, can thiệp tái thông mạch vành khi có chỉ định.

Dựa vào chẩn đoán cuối cùng, chúng tôi sẽ tiến hành nghiên cứu giá trị chẩn đoán của dấu hiệu Chapman (độ nhạy, độ đặc hiệu, tiên đoán dương, tiên đoán âm, tî số khả dĩ dương, tỉ số khả dĩ âm) và so sánh với các tiêu chuẩn khác. Các kiểm định thống kê y học sẽ được sử dụng với mức ý nghĩa $p<0,05$.

Dấu Chapman. Dấu Chapman là hình ảnh một móc $(\geq 0,05 \mathrm{~s})$ ở phần lên của sóng $R$ trên các chuyển đạoDI, $\mathrm{aVL}$ hoặc V6.Tiêu chuẩn Chapman có thể giúp chẩn đoán NMCT ở những bệnh nhân cóBNT và không đáp ứng các tiêu chuẩn Sgarbossa cải tiến.

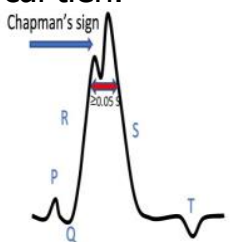

Hình 1. Hình ảnh dấu Chapman trên ĐTĐ

\section{KẾT QUẢ NGHIÊN CứU}

3.1. Đặc điểm chung của đối tượng nghiên cứu

Bảng 16. Đăc điểm chung nhóm nghiên cứu

\begin{tabular}{|c|c|c|c|c|c|c|c|}
\hline & \multicolumn{3}{|c|}{ Nhóm NMCT } & \multicolumn{3}{c|}{ Nhóm không NMCT } & \\
\hline & N & TB & I SD & N & TB & 土 SD & p \\
\hline Tuối (năm) & 79 & 68,42 & 11,88 & 71 & 64,21 & 13,74 & $\mathbf{0 , 0 4 6}$ \\
\hline
\end{tabular}


VIETNAM MEDICAL JOURNAL N²2 - NOVEMBER - 2021

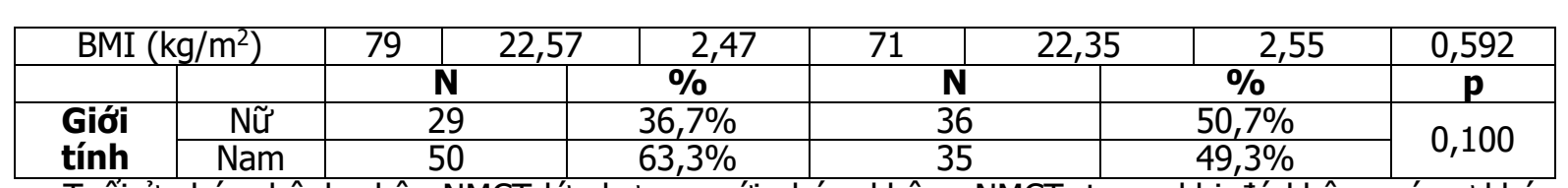

Tuối ở nhóm bênh nhân NMCT lớn hơn so với nhóm không NMCT, trong khi đó không có sự khác biệt về phân bố giới tính.

\section{2. Đặc điếm điện tâm đồ trên bệnh nhân NMCT kèm BNT}

Bàng 2̇. Đặc điểm về điện tâm đồ ở nhóm ĐTNC

\begin{tabular}{|c|c|c|c|c|c|c|c|c|c|}
\hline & & \multicolumn{4}{|c|}{ Nhóm NMCT } & \multicolumn{3}{|c|}{ Nhóm không NMCT } & $\mathbf{p}$ \\
\hline & & $\mathbf{N}$ & \multicolumn{2}{|c|}{ TB } & \pm SD & $\mathbf{N}$ & TB & \pm SD & \\
\hline \multicolumn{2}{|l|}{ Tần số (ck/phút) } & 79 & \multicolumn{2}{|c|}{84.09} & 13.57 & 71 & 87.34 & 18.06 & 0.212 \\
\hline \multicolumn{2}{|l|}{ Khoảng PR (ms) } & 76 & \multicolumn{2}{|c|}{169.79} & 32.46 & 66 & 170.85 & 31.99 & 0.846 \\
\hline \multicolumn{2}{|l|}{ Khoảng QRS (ms) } & 79 & \multirow{2}{*}{\multicolumn{2}{|c|}{$\begin{array}{l}134.18 \\
458.47\end{array}$}} & 14.55 & 71 & 128.15 & 18.29 & 0.028 \\
\hline \multirow[t]{3}{*}{ Khoảng QTC (ms) } & & 78 & & & 54.03 & 70 & 463.41 & 29.90 & 0.499 \\
\hline & \multirow{2}{*}{\multicolumn{3}{|c|}{\begin{tabular}{c|c}
\multicolumn{2}{|c|}{ Nhóm chung } \\
$\mathbf{N}$
\end{tabular}}} & \multicolumn{2}{|c|}{ Nhóm NMCT } & \multirow{2}{*}{\multicolumn{3}{|c|}{ Nhóm không NMCT }} & \\
\hline & & & $\%$ & $\mathbf{N}$ & $\%$ & & & $\%$ & $\mathbf{p}$ \\
\hline Trục trung gian & 74 & & $3 \%$ & 40 & $50.6 \%$ & & 34 & $47.9 \%$ & \\
\hline Trục trái & 76 & & $.7 \%$ & 39 & $49.4 \%$ & & 37 & $52.1 \%$ & 0.147 \\
\hline Nhịp xoang & 141 & & $3 \%$ & 76 & $97.4 \%$ & & 65 & $92.9 \%$ & 0250 \\
\hline Rung nhĩ & 7 & & $7 \%$ & 2 & $2.5 \%$ & & 5 & $7.0 \%$ & 0.256 \\
\hline
\end{tabular}

Nhìn chung, đă̆c điếm về các chỉ số ĐTĐ như tần số, trục điện tim, các thời khoảng không có sự khác biệt giữa nhóm có và không có NMCT.

Bảng 3. Tần suất xuất hiện các tiêu chuẩn NMCT trên ĐTĐ có BNT

\begin{tabular}{|c|c|c|c|c|c|}
\hline & \multicolumn{2}{|c|}{ Nhóm NMCT } & \multicolumn{2}{c|}{ Nhóm không NMCT } & \\
\hline & $\mathbf{N}$ & $\mathbf{\%}$ & $\mathbf{N}$ & $\mathbf{\%}$ & $\mathbf{p}$ \\
\hline & 1 & $1.3 \%$ & 0 & $0.0 \%$ & 0.342 \\
\hline Sgarbossa 5 điếm & 1 & $1.3 \%$ & 0 & $0.0 \%$ & 0.342 \\
\hline Sgarbossa 3 điếm & 1 & $1.3 \%$ & 1 & $1.4 \%$ & 0.939 \\
\hline Sgarbossa 2 điếm & 2 & $2.5 \%$ & 0 & $0.0 \%$ & 0,498 \\
\hline Smith I & 3 & $3.8 \%$ & 0 & $0.0 \%$ & 0,247 \\
\hline Smith II & 6 & $7.6 \%$ & 1 & $1.4 \%$ & 0,119 \\
\hline Smith III & 7 & $8.9 \%$ & 0 & $0.0 \%$ & 0,014 \\
\hline Smith IV & 10 & $12.7 \%$ & 4 & $5.6 \%$ & 0.140 \\
\hline Smith V & 31 & $39.2 \%$ & 32 & $45.1 \%$ & 0.470 \\
\hline Chapman & 0 & $0.0 \%$ & 0 & $0.0 \%$ & \\
\hline Cabrera & 30 & $38.0 \%$ & 13 & $18.3 \%$ & $\mathbf{0 . 0 0 8}$ \\
\hline Barcelona tiêu chuấn 2 & 30 & & & 0
\end{tabular}

Trong các tiêu chuấn chấn đoán NMCT kèm BNT được đánh giá, tiêu chuấn Chapman và Barcelona 2 và Smith $V$ có tần suất xuất hiện nhiều nhất.

3.3. Giá trị chẩn đoán của các tiêu chuẩn chẩn đoán NMCT kèm BNT

Bảng 4. Giá trị chẩn đoán của các tiêu chuẩn chẩn đoán NMCT có BNT

\begin{tabular}{|c|c|c|c|c|c|c|}
\hline \multirow{2}{*}{} & \multicolumn{7}{|c|}{ Giá trị chấn đoán } \\
\cline { 2 - 7 } & Se (\%) & Sp (\%) & PPV (\%) & NPV (\%) & LR+ & LR- \\
\hline Sgarbossa 5 điếm & 1,3 & 100,0 & 100,0 & 47,7 & & 0,99 \\
\hline Sgarbossa 3 điếm & 1,3 & 100,0 & 100,0 & 47,7 & & 0,99 \\
\hline Sgarbossa 2 điếm & 1,3 & 98,6 & 50,0 & 47,3 & 0,90 & 1,00 \\
\hline Smith III & 7,6 & 98,6 & 85,7 & 49,0 & 5,39 & 0,94 \\
\hline Smith IV & 8,9 & 100,0 & 100,0 & 49,7 & & 0,91 \\
\hline Smith V & 12,7 & 94,4 & 71,4 & 49,3 & 2,25 & 0,93 \\
\hline Chapman & 39,2 & 54,9 & 49,2 & 44,8 & 0,87 & 1,11 \\
\hline LBBB mới xuất hiện & 3,8 & 100,0 & 100,0 & 48,3 & & 0,96 \\
\hline Giảm biên độ sóng R & 2,5 & 97,2 & 50,0 & 47,3 & 0,90 & 1,00 \\
\hline Barcelona tiêu chuẫn 2 & 38,0 & 81,7 & 69,8 & 54,2 & 2,07 & 0,76 \\
\hline
\end{tabular}

Trong nghiên cứu, tiêu chuấn Chapman và Barcelona 2 có độ nhạy chấn đoán cao nhất (lần lượt là $39,2 \%$ và $38,0 \%)$. Tuy vậy, độ đặc hiệu của tiêu chuẩn Chapman chỉ đạt (54,9\%). Khi so sánh giá trị chẩn đoán, các tiêu chuấn Smith III có tỉ số khả chỉ chẩn đoán dương tính cao nhất $(5,39)$. 


\section{BÀN LUÂN}

Nếu chỉ dựa vào điện tâm đồ, việc chẩn đoán NMCT trên những bệnh nhân có BNT hoàn toàn hiện nay vẫn là một thách thức. Qua nhiều năm, nhiều tác giả đã đề xuất những tiêu chuẩn hoăc các dấu hiệu khác nhau giúp chẩn đoán NMCT trên bệnh nhân có BNT. Tuy nhiên, cho đến nay, vẫn chưa có tiêu chuẩn nào cho thây khả năng chẩn đoán tốt với bối cảnh lâm sàng này. Theo kết quả nghiên cứu của chúng tôi, các thông số cơ bản của điện tâm đồ (tần số, khoảng $P R$, QTc, nhịp xoang, trục trung gian) không có sự khác biệt của 2 nhóm $(p>0,05)$, ngoại trừ khoảng QRS ở nhóm NMCT lớn hơn so với nhóm không NMCT $(p<0,05)$. Trong các tiêu chuẩn chẩn đoán NMCT kèm BNT (Bảng 2), dấu hiệu xuất hiện phổ biến là dấu Chapman (39,2\%). Kết quả này cũng tương đương với các nghiên cứu khác, khi cho thấy tần suất xuất hiện của các dấu hiệu trên ĐTĐ là không rõ ràng. Chính điều này sẽ khiến cho độ nhạy trong các chẩn đoán tương đối thấp, và đây là một thách thức trong tiếp cận chẩn đoán, điều trị bệnh nhân NMCT kèm BNT.

Giá trị chẩn đoán của dấu Chapman và các dấu hiệu khác trên ĐTĐ NMCT kèm BNT. Trong các tiêu chuẩn được đánh giá trong nghiên cứu, độ nhạy chẩn đoán cao nhất là các dấu Chapman $(39,24 \%)$, tiêu chuẩn Barcelona $2(37,97 \%)$ và tiêu chuẩn Smith V $(12,66 \%)$. Độ đặc hiệu cao nhất là tiêu chuẩn sagarbossa và các tiêu chuẩn smith. Tỉ số khả dĩ chẩn đoán dương cao nhất là tiêu chuẩn smith III $(5,39)$, tiêu chuẩn smith V $(2,25)$, tiêu chuẩn barcelona $2(2,07)$ (Bảng 3$)$.

Điều khác biệt trong nghiên cứu của chúng tôi có thể thấy là sự xuất hiện của dấu Chapman. Trong đó, dấu Chapman cho thây có độ nhạy $39,2 \%$ và độ đặc hiệu $54,9 \%$. Dâu Chapman là dấu hiệu trên điện tim được mô tả lần đầu tiên vào năm 1957 của tác giả Myron g. Chapman ${ }^{4}$ cho thấy nó có sự liên quan đến tổn thương NMCT thành trước. Theo nghiên cứu của Ivanov và cộng sự, dấu hiệu Chapman có độ nhạy thấp (khoảng $3 \%$ ), nhưng độ đặc hiệu cao, có thể lên tới $92 \%$ \% năm 2003 cũng cho thấy dấu hiệu Chapman có độ nhạy thấp $(21 \%)$ nhưng có độ đặc hiệu cao $(92 \%)$, tỉ số khả dĩ chẩn đoán dương $0,4(0,1-$ $3,8)$, tỉ số khả dĩ chẩn đoán âm $1,04(0,96-1,15)$. Kết quả nghiên cứu của Shlipak ${ }^{7}$ năm 1999 cho thấy độ nhạy của dấu Chapman chỉ có $3 \%$. Giá trị chẩn đoán của dấu Chapman thay đổi khá nhiều ở mỗi nghiên cứu. Qua đây, ta cũng có thể nhận ra dấu Chapman có liên quan đến tổn thương NMCT do động mạch liên thất trước, và thường nó là dấu hiệu của NMCT cũ. Có lẽ chính vì điều đó, khi đối tượng nghiên cứu của chúng tôi có tỉ lệ bệnh nhân tổn thương LAD cao đã giải thích cho độ nhạy trong chẩn đoán của dấu hiệu này có phần cao hơn một số nghiên cứu khác.

Độ nhạy và độ đặc hiệu khi chỉ sử dụng đơn độc Đ̇TĐ trong chẩn đoán NMCT kèm BNT qua các kết quả ở trên nghiên cứu chúng tôi hay các tác giả khác là không cao và giá trị thay đổi qua nhiều nghiên cứu. Do đó, việc kết hợp các phương tiện chẩn đoán khác như men tim hay siêu âm tim là một giải pháp hơp lý. Nghiên cứu của Nestelberger ${ }^{8}$ và cộng sự năm 2019, ĐTĐ để chẩn đoán NMCT cấp kèm BNT có độ nhạy thấp (1-2\%) nhưng có độ đặc hiệu cao (95-100). Để khắc phục độ nhạy thấp, tác giả đã kết hợp với men tim và siêu âm thì độ nhạy của chẩn đoán cải thiện một cách đáng kể. Tương tự trong nghiên cứu của Poprawski ${ }^{9}$ cũng cho thây khi phối hợp 2 hay 3 phương pháp sẽ làm tăng độ nhạy lền $99-100 \%$. Nghiên cứu của chúng tôi cũng cho kết quả tương tự.

\section{KẾT LUÂ̂N}

Dấu hiệu Chapman là một dấu hiệu thường gặp hơn các dấu hiệu khác trên ĐTÐ của bệnh nhân NMCT kèm BNT. Dâu hiệu cho thây có giá trị không cao trong chẩn đoán NMCT. Việc kết hợp các thông tin khác như men tim hay siểu âm tim là cần thiết trong chẩn đoán kịp thời các bệnh nhân NMCT kèm BNT.

\section{TÀI LIỆU THAM KHẢO}

1. Nguyễn Lân Việt, Phạm Việt Tuân, Phạm Mạnh Hùng, Văñ Đức Hạnh \& Nguyến Ngọc Qúang. Nghiên cứu mô hình bệnh tật ở bệnh nhân điều trị nội trú tại Viện tim mạch Việt Nam trong thời gian 2003-2007. Tạp chí Tim mạch học Việt Nam 11-18 (2010). 2. Wellens, H. J. J., Gorgels, A. M. \&
Doevendans, P. A. F. M. The ECG in Acute Myocardial Infarction and Unstable Angina: Diagnosis and Risk Stratification. (Springer US, 2002). doi:10.1007/b101885.

3. Idris, A., Hatahet, M. \& Edris, B. Acute myocardial infarction in the setting of left bundle branch block: Chapman's sign. The American Journal of Emergency Medicine37, 1991.e5-1991.e7 (2019).

4. Chapman, M. G. \& Lee Pearce, $\mathbf{M}$. Electrocardiographic Diagnosis of Myocardial Infarction in the Presence of Left Bundle-Branch Block. Circulation16, 558-571 (1957).

5. Ivanov, I. et al. Electrocardiographic signs of acute myocardial infarction in left bundle branch block. Med. Pregl.66, 503-506 (2013).

6. Maynard, S. J. et al. Body surface mapping improves early diagnosis of acute myocardial infarction in patients with chest pain and left bundle branch block. Heart89, 998-1002 (2003). 
7. Shlipak, M. G. et al. Should the Electrocardiogram Be Used to Guide Therapy for Patients With Left Bundle-Branch Block and Suspected Myocardial Infarction? JAMA281, 714719 (1999).

8. Nestelberger, T. et al. Diagnosis of acute myocardial infarction in the presence of left bundle branch block. Heart105, 1559-1567 (2019)

9. Poprawski, K., Piszczek, I., Smukowski, T. \& Paradowski, S. Comparison of the diagnostic value of echocardiographic, ecg and enzymatic investigations in acute myocardial infarction. Pol Arch Med Wewn85, 167-173 (1991).

\section{ĐẶC ĐIỂM LÂM SÀNG VÀ CÂN LÂM SÀNG CỦA VIÊM ÂM ĐẠO KHÔNG ĐẶC HIỆU TẠI BỆnH VIỆN DA LIỄU TRUNG ƯƠ'NG}

\section{TÓM TẮT}

Mục tiêu: Mô tả đặc điểm lâm sàng và cân lâm sàng của viêm âm đạo không đặc hiệu tại Bệnh viện Da liễu Trung ương từ tháng 8/2020 - 8/2021. Đối tượng và phương pháp: Mô tả cắt ngang trên 39 bệnh nhân được chẩn đoán xác định viêm âm đạo không đăc hiệu bằng tiêu chuẩn Amsel đến khám trong thời gian nghiên cứu. Kết quả: Bệnh thường gặp ở nhóm tuối từ 18-30 tuối $(66,6 \%)$. Tiền sử sản phụ khoa liên quan nạo hút thai $33,3 \%$, sảy thai $10,3 \%$. Đa số bênh nhân có triêu chứng cơ năng $(61,5 \%)$, trong đó, thường gặp mùi khí hư $(79,5 \%)$, ngứa rát âm hộ $(48,7 \%)$, giao hợp đau $(33,3 \%)$. Khám âm hộ âm đạo phát hiện $61,5 \%$ trường hợp viêm đỏ, đa số dịch nhiêu $69,2 \%$. Test sniff và tế bào clue dương tính ở $100 \%$ trường hợp, $66,7 \%$ có số lượng trực khuẩn gram âm từ 2+ trở lên, $94,9 \%$ số lượng lactobacilli từ 1+ trở xuống, độ lactobacilli IIb chiếm $51,3 \%$, độ III 23,1\%. Phân loại hệ vi sinh vật theo Nugent có $59 \%$ từ $4-6$ điểm và $41 \%$ từ $7-10$ điểm. Kết luận: Viêm âm đạo không đặc hiệu có xu hướng gặp ở phụ nữ trẻ, liên quan đến tiền sử thai sản và có biểu hiện rối loạn hệ vi sinh vật tại âm đạo.

Tứ khóa: Viêm âm đạo khổng đặc hiệu, lactobacilli

\section{SUMMARY}

\section{CLINICAL AND SUBCLINICAL CHARACTERISTICS} OF PATIENT WITH BACTERIAL VAGINOSIS AT NATIONAL HOSPITAL OF DERMATOLOGY AND VENEREOLOGY

Objectives: To investigate clinical and subclinical characteristics of bacterial vaginosis (BV) at National Hospital of Dermatology and Venereology from August 2020 to August 2021. Population and methods: Cross-sectional description of thirdty-nine patients with bacterial vaginosis who were diagnosis by Amsel'criteria. Results: BV was common in the age group of $18-30$ years old (66.6\%). History of obstetrics and gynecology related to abortion 33.3\%,

*Đại học Y Hà Nội

**Bệnh viện Da liễu Trung Uơng

Chịu trách nhiệm chính: Trần Cẩm Vân

Email: trancamvan.dl@gmail.com

Ngày nhận bài: 24.8.2021

Ngày phản biên khoa hoc: 18.10.2021

Ngày duyệt bài: 29.10.2021

\section{Trần Thị Lệ Giang*, Trần Cẩm Vân**}

miscarriage $10.3 \%$. The majority of patients had patient's symptoms $(61.5 \%)$, in which, vaginal odor $(79.5 \%)$, itching $(48.7 \%)$, painful intercourse $(33.3 \%)$ were common. Vaginal examination detected $61.5 \%$ of cases of red inflammation, most of the fluid was $69.2 \%$. Sniff test and clue cells were positive in $100 \%$ of cases, $66.7 \%$ had gram-negative bacilli of $2+$ or more, $94.9 \%$ had $1+$ or less of lactobacilli, lactobacilli IIb accounted for $51.3 \%$, grade III $23.1 \%$. Classification of microorganisms according to Nugent had $59 \%$ from $4-6$ points and $41 \%$ from $7-10$ points. Conclusion: Bacterial vaginosis tends to be seen in younger women, is associated with a history of pregnancy, and presents with disturbances in the vaginal flora.

Key words: Bacterial vaginosis, lactobacilli

\section{I. ĐẶT VẤN ĐỀ}

Viêm âm đạo không đặc hiệu (Bacterial vaginosis-BV) là một dạng thường gặp của viêm âm đạo, đặc trưng bởi sự mất cân bằng vi hệ tự nhiên tại âm đạo. Nguyên nhân là do suy giảm số lượng vi khuẩn lactobacilli và phát triển quá mức của nhiều nhóm vi khuẩn khác nhau trong đó đăc biệt Gardnerella vaginalis, vi khuẩn ki khí, Mycoplasma hominis [1]. Theo Javed (2019), viêm âm đạo không đặc hiệu là bệnh lý thường găp ở phu nữ, ước tính có từ $5-70 \%$ phư nữ mắc ít nhất một lần trong đời [1]. Ước tính có khoảng 21,2 triệu phụ nữ trên toàn thế giới hiện mắc. Các triệu chứng lâm sàng của bệnh khổng đặc hiệu như ngứa, kích thích, bỏng rát và tiết dịch bất thường ở âm hộ, âm đạo. Do đó, bệnh thường xuyên tái phát, dẫn tới sinh non, phá thai, rối loạn viêm vùng chậu hông và nhiễm trùng sau sinh [1],[2]. Tại Việt Nam, các báo cáo của Lê Hiếu Hạnh và cộng sự (2019), Đinh Thị Huyền Ngọc và cộng sự (2013) cho thấy viêm âm đạo không đặc hiệu thường gặp ở phụ nữ trong độ tuổi sinh sản, có tiền sử sản phụ khoa liên quan sảy thai, sinh non, đa phân xuất hiện không triệu chứng và chủ yếu chẩn đoán bằng các xét nghiệm cận lâm sàng như test sniff, tìm tế bào clue hay nhuộm gram [3],[4]. Do đó, 